\title{
Juventude, cultura e profissionalização da criatividade
}

\author{
Carla Regina Silva, Isadora Cardinalli, Marina Sanches Silvestrini, Aline Zacchi Farias, \\ Débora Isabele de Vasconcelos Teixeira, Ana Carolina da Silva Almeida Prado, \\ Leticia Ambrosio, Rúbia Diana da Mota, Caio de Camargo Ishido, \\ Marco Antonio Liu Targa Mancini
}

Universidade Federal de São Carlos - UFSCar, São Carlos, SP, Brasil.

\begin{abstract}
Resumo: Este artigo integra reflexões sobre a juventude, o trabalho e a cultura a partir do conceito de profissionalização da criatividade. Afinal, a educação e o trabalho são temas centrais para a juventude que possui dificuldades reais de inserção, e a cultura tem sido apontada como essencial para o desenvolvimento das sociedades. Para tanto, apresenta-se uma pesquisa que teve o intuito de contribuir para a compreensão acerca de jovens gestores e produtores culturais por meio de um mapeamento na cidade de São Carlos (SP - Brasil). A metodologia consistiu em: i) mapeamento de programas, serviços e ações artístico- culturais dos diferentes setores, destinadas ou protagonizadas por jovens, com aplicação de um questionário específico; e ii) entrevistas com os artistas (15 a 29 anos), residentes na cidade e com interesse na profissionalização. Foram indicados 210 jovens artistas, realizadas 96 entrevistas e encontrados 46 jovens no perfil. As análises consideraram os artistas a partir de suas produções artísticas e das categorias: identificação, estrutura, profissionalização e financiamento. As demandas estiveram marcadas pela dificuldade de financiamento e gestão, o que acarreta numa precarização do trabalho em diferentes âmbitos. Ao mesmo tempo, sonhos, satisfação, cunho ideológico de transformação social e sublimação da vida fortalecem esses jovens na luta pela profissionalização de sua arte. Corrobora-se, portanto, com o investimento público para a cultura na direção do potencial transformador de processos culturais que produzem deslocamentos sensíveis. Além de estratégias visando ao desenvolvimento e ao impacto social, somando, portanto, importantes saberes e práticas para a terapia ocupacional.
\end{abstract}

Palavras-chave: Arte, Cultura, Criatividade, Condições de Trabalho, Juventude.

\section{Youth, culture and creativity professionalization}

\begin{abstract}
This article links reflections on youth work and culture from the concept of the creativity professionalization. After all, education and work are central themes for youth with real insertion problems; and culture has been pointed as essential for societies' developments. Therefore, we present a search that aimed to contribute to the understanding of young managers and cultural producers through a mapping in the city of São Carlos (SP - Brazil). The methodology consisted of: i) mapping of programs, services and cultural artistic actions, from the different sectors, designed for or protagonized by young people, by applying a specific questionnaire; and ii) artists' interviews (15 to 29 years), living in the city and with professionalization interests. From the mapping of these sectors, 210 young artists were indicated, with 96 conducted interviews and 46 young matching the profile. The analysis considered the artists from their artistic productions and the categories: identification, structure, professionalization and financing. The demands were marked by the financing and management difficulty which results in work precariousness in different areas, at the same time, dreams, satisfaction, ideological social transformation and sublimation of life, strengthen these young people in the struggle for professionalization of their art. It contributes, therefore, with public investment for the culture toward the transformative potential of cultural processes that produce sensitive displacement. In addition to strategies for development and social impact, adding, therefore, important knowledge and practices for occupational therapy.
\end{abstract}

Keywords: Art, Culture, Creativity, Working Conditions, Youth.

Autor para correspondência: Carla Regina Silva, Laboratório Atividades Humanas e Terapia Ocupacional, Departamento de Terapia Ocupacional, Universidade Federal de São Carlos, Rodovia Washington Luís, Km 235, SP-310, CEP 13565-905, São Carlos, SP, Brasil, e-mail: carlars@ufscar.br

Recebido em Maio 28, 2015; $1^{\text {a }}$ Revisão em Jul. 30, 2015; 2 ${ }^{\text {a }}$ Revisão em Out. 15, 2015; Aceito em Out. $30,2015$. 


\section{Juventude e trabalho}

O presente artigo debate a juventude e sua precária inserção no trabalho associados às novas estratégias voltadas para o campo da cultura. A juventude será compreendida dada sua força numérica, importância geracional, relevância social, política e econômica e curso da vida marcada pela construção da identidade e desenvolvimento das bases de como o indivíduo irá se relacionar com e no mundo em todos os setores da sociedade (GROPPO, 2007; CORROCHANO, 2013).

Ressalta-se os debates da cultura juvenil apresentados por Pais (1990), que considera a estrutura de classes, o meio social de origem e o sistema de valores socialmente dominantes atribuídos à juventude, que serão mais ou menos prevalecentes e diferentemente vividos segundo as trajetórias e condiçóes em que os jovens estão inseridos, compreendendo seus modos de vidas e cotidiano, a partir de seus processos de socialização.

O Estatuto da Juventude demarca no Brasil a juventude entre os 15 e os 29 anos, sendo considerados jovens os adolescentes-jovens (entre 15 e 17 anos), os jovens-jovens (entre 18 e 24 anos) e os jovens-adultos (entre 25 e 29 anos) (BRASIL, 2013). Atualmente, se considerarmos a pirâmide populacional do país, temos que nesse grupo se concentra o maior percentual de brasileiros, cerca de 51 milhōes de pessoas (BRASIL, 2013). A importância numérica dos jovens náo pode ser considerada problema; a relação se estabelece quando as oportunidades são escassas, restritas e finitas, questôes das quais a educação e o trabalho são protagonistas.

Corrochano (2013) aponta que a atuação dos jovens no mercado atual se transformou em um processo de inserçáo profissional cada vez mais longo, difícil e aleatório, diferente das décadas anteriores, quando a inserção em uma ocupação regular ao final da escolarização obrigatória era quase imediata. Ainda assim, é preciso considerar a restrição da formalizaçáo educacional, que ocorria apenas para determinada parcela da populaçáo (MARCÍlIO, 2005).

Esse percurso, historicamente, se correlaciona à classe social a que pertence o jovem. Antes de atingirem 18 anos de idade, muitos jovens já se dividem entre o estudo e o trabalho, porém, a partir dos 18 anos, estudar torna-se privilégio de uma parcela ainda menor. Entre aqueles de 18 e 19 anos, 25,8\% têm como atividade exclusiva o estudo e, no grupo de 20 a 24 anos, apenas 10,1\% (INSTITUTO..., 2008). Observa-se que jovens de 14 a 17 anos que só trabalham - a grande maioria sem ter concluído o ensino fundamental - localizam-se majoritariamente entre os $40 \%$ com menor renda familiar per capita. Aqueles com maior renda tendem a se dedicar de forma exclusiva ao trabalho somente a partir dos 18 anos, depois de terem garantido sua educação básica. Os dados tornam evidente que jovens de mais baixa renda começam a trabalhar mais cedo e, majoritariamente, sem concluir os estudos (CORROCHANO et al., 2008). Em termos relativos, os jovens apresentam altas taxas de desocupação, informalidade e níveis de rendimento inferiores à média da população trabalhadora (ORGANIZAÇÃO..., 2009).

A população jovem pobre é a mais vulnerável e apresenta maior desvantagem, afinal possui menos experiência profissional, pouca qualificação, baixa escolarização, menores índices de estabilidade e de oportunidades, funções menos prestigiadas e menos remuneradas, absorção informal, irregularidade de funçôes ou do trabalho, num ciclo contínuo de exclusão e inserção precária no mundo do trabalho (SILVA; LOPES, 2009, p. 96).

A crise financeira global e a desaceleração da economia produziram o maior contingente de jovens desempregados da história: em 2009 havia 80,7 milhóes de jovens lutando por um trabalho, muitos deles se veem obrigados a emigrar em busca de oportunidades e às vezes em condições perigosas ou de exploração (ORGANIZAÇÃO..., 2013).

Juan Somavia, diretor-geral da Organização Internacional do Trabalho - OIT, na apresentação do relatório Tendências Mundiais de Emprego de 2010, afirma:

Com 45 milhóes de jovens mulheres e homens entrando no mercado de trabalho global a cada ano, as medidas de recuperaçáo devem mirar a criação de empregos para nossos jovens (ORGANIZAÇÃO..., 2009).

\section{Cultura e desenvolvimento}

A cultura tem sido apresentada como uma estratégia para o desenvolvimento, inclusive para as demandas apontadas para a juventude em documentos nacionais ou internacionais.

A Agenda 21 da Cultura ${ }^{1}$ apresenta como seu princípio $10^{\circ}$. Que:

A afirmação das culturas, assim como o conjunto das políticas que foram postas em prática para o seu reconhecimento e 
viabilidade, constitui um fator essencial no desenvolvimento sustentável das cidades e territórios no plano humano, econômico, político e social. O caráter central das políticas públicas de cultura é uma exigência das sociedades no mundo contemporâneo (FÓRUM..., 2004, p. 5).

A Conferência das Naçôes Unidas para o Comércio e Desenvolvimento em 2004 corrobora com essa perspectiva da cultura, incentivando a criação de programas e atividades que envolvam a implementação de setores criativos que contribuam para esse desenvolvimento (UNESCO, 2013). Importante referência para a construção da pauta da Economia Criativa ${ }^{2}$ no país.

O Plano Nacional de Economia Criativa (BRASIL, 2011, p. 22) define este como um campo representativo dos diversos conjuntos de empreendimentos nos "setores criativos", ou seja, atividades produtivas que têm como

processo principal um ato criativo gerador de um produto, bem ou serviço, cuja dimensão simbólica é determinante do seu valor, resultando em produçáo de riqueza cultural, econômica e social.

O Governo Federal divulga que "[...] a cultura pode ser usada para incentivar o desenvolvimento econômico justo e sustentável de um país" (PORTAL..., 2009). As atividades culturais são estratégicas e geram trabalho, emprego e renda, além de promover a inclusão social, especialmente entre jovens. No Brasil, o crescimento médio anual dos setores criativos $(6,13 \%)$ foi superior ao aumento médio do PIB nacional (cerca de 4,3\%) nos últimos anos (PORTAL..., 2009).

O Ministério do Trabalho e Emprego afirma que "[...] há o consenso de que as dimensóes trabalho, cultura e educação sejam pilares das políticas dirigidas à juventude" (COSTANZI, 2009, p. 159).

A Política Nacional da Juventude (BRASIL, 2006) reforça que na juventude devem ser garantidas como direito as formaçôes educacional e cultural, pois a cultura relaciona-se com a formação, a criação e a economia (produção cultural), e é sem dúvida um elemento estruturante da vivência juvenil e aponta a necessidade do estímulo e espaços culturais para os jovens e a criaçáo de programas que permitam essa profissionalização da criatividade por meios artísticos.

O Plano Nacional de Cultura (BRASIL, 2010) apresenta em seu artigo primeiro - desenvolver a economia da cultura, o mercado interno, o consumo cultural e a exportação de bens, serviços e conteúdos culturais. O desenvolvimento é entendido não apenas como econômico, mas também que promova um ambiente democrático de respeito às diferentes opiniōes, proporcionando a possibilidade de ideias individuais, a liberdade, o bem-estar social e a organização política e da sociedade.

Assim, tal como apontado por Souza e Carrieri (2011), o Brasil entende e assume a expansão de setores criativos e culturais como potencial de geração de empregos, consumo e um espaço de criaçáo para os envolvidos.

\section{Profissionalização da criatividade}

Segundo Almeida e Pais (2012), os processos criativos, a criação e a criatividade no mundo contemporâneo estão adquirindo novas dimensóes de organizaçóes produtivas que permitem uma ampliação de trabalho para o público jovem. Isto se deve ao fato de esses processos estarem sendo explorados sob a ótica da possibilidade de geraçáo de renda através de práticas profissionalizantes que regulam esta profissionalização criativa por meio dos mecanismos de subjetivação da criação dos sujeitos, e que está sendo cada vez mais utilizada em espaços empresariais (ALMEIDA; PAIS, 2012).

Para De Massi (2002), o fato de a criatividade possuir um papel fundamental e de destaque que antes náo possuía, deve-se ao fato de ser considerada força motriz para a Economia Criativa.

Por outro lado, sabemos que a cultura também enfrenta inúmeros desafios em sua constituição como política social, há contraposiçóes em relação a sua função social demarcadas pelas questóes macroeconômicas calcadas pela lógica capitalista e neoliberal que determinam produtividade, crescimento e globalização da economia, exploraçáo do trabalho, investimentos do capital, e que interferem e por vezes determinam os processos de gestão, produção, circulaçáo e até mesmo fruição dos bens culturais e seus processos de trabalhos.

Como reflexo, temos que o emprego formal na cultura apresenta dinamismo menor do que no conjunto dos empregos formais, e o emprego cultural reage com maior intensidade aos períodos de crescimento ou baixo ritmo de crescimento da economia (BRASIL, 2007), demonstrando sua instabilidade e fragilidade ${ }^{3}$.

Corrobora-se com os desafios colocados por Canclini (2003), que aponta a necessidade de: a) Identificar as áreas estratégicas de nosso desenvolvimento, ressaltando 
as necessidades humanas, colocando no centro as pessoas e as sociedades, não os investimentos, nem outros indicadores financeiros ou macroeconômicos; b) Desenvolver políticas socioculturais que promovam o avanço tecnológico e a expressão multicultural de nossas sociedades, centradas no crescimento da participação democrática dos cidadãos.

As iniciativas de institucionalização, formalização e implementação de políticas culturais devem reconhecer que quanto mais denso, diverso e rico o conteúdo, maiores suas possibilidades de desenvolvimento. Contudo, o potencial produtivo, empregador e inovativo das atividades culturais e criativas é pouco estudado, por isso, temos a necessidade de conceber novos instrumentos, metodologias e indicadores capazes de entender e promover tais atividades (BRASIL, 2011).

De acordo com Coelho (2003), para que as políticas culturais possam alavancar um desenvolvimento nacional, entendido como um dos motores do desenvolvimento maior, é imprescindível a existência de dados sobre a cultura, ou seja, indicadores de um conhecimento analítico da dinâmica sociocultural, e que esses, por sua vez, sejam capazes de direcionar a formulação de políticas culturais e políticas socioculturais.

\section{Mapeamento da cultura}

Segundo o Ministério da Cultura (BRASIL, 2013), o mapeamento do campo cultural possui grande contribuição para conhecer e mensurar as atividades culturais que ocorrem, e assim obter parâmetros e detectar as necessidades culturais e sociais em um determinado local. Somada a possibilidade de, a partir dos dados obtidos, que sejam realizadas formulaçóes, monitoramento, gestão e avaliação das políticas públicas de cultura e das políticas culturais.

O Sistema Nacional de Informaçôes e Indicadores Culturais (SNIIC) ${ }^{4}$ foi gestado para possibilitar a produção de estatísticas, indicadores e outros dados sobre as atividades da cultura, com o objetivo de auxiliar no monitoramento e na avaliação do Plano Nacional de Cultura (BRASIL, 2015).

Contudo, essa não é uma tarefa fácil, pois não temos no Brasil uma tradição nas avaliaçôes de políticas públicas, o que dificulta estudos longitudinais, comparaçóes e outros formatos avaliativos das políticas. Isso ocorre também com o setor cultural.

Lins (2006) aponta que diversos países possuem lacunas nas análises econômicas da cultura, sobretudo nas informações estatísticas sobre a produção e o consumo de bens e serviços culturais. No Brasil, também a produção de informaçôes e indicadores culturais não existe de forma sistemática, atualizada e coordenada.

\section{Mapeamento dos produtores jovens de arte e cultura}

As reflexôes até aqui apresentadas foram estruturantes para a realização de um conjunto de açóes integradas entre ensino, pesquisa e extensão, que propôs realizar um mapeamento das atividades artístico-culturais protagonizadas por jovens (15 a 29 anos) na cidade de São Carlos - SP. Além disso, objetivou identificar e analisar o potencial de geração de renda e de profissionalização da atividade artística exercida, valorizando o protagonismo juvenil para a inserção no mercado de trabalho e a qualificação profissional cultural.

As atividades estiveram vinculadas: i) ao Programa de Extensão Universitária Arte, Cultura, Juventude e Empreendimentos Criativos'; ii) à Pesquisa Juventude, Trabalho e Profissionalizaçâo da Criatividade, junto com outras quatro Iniciaçôes Científicas ${ }^{6}$ desenvolvidas entre 2013 e 2015; iii) e à oferta da Atividades Curriculares Integradas de Ensino, Pesquisa e Extensão - ACIEPE Arte, cultura, juventude e trabalho ${ }^{7}$.

A importância do Mapeamento esteve diretamente relacionada com um diagnóstico pioneiro sobre arte e cultura na cidade, além disso, possibilitou maior compreensão sobre as artes produzidas, qual inserção dos jovens na lógica de mercado da cultura, suas perspectivas e possibilidades de profissionalização da criatividade. Além disso, estabeleceu ponte entre universidade e comunidade, bem como investiu na formação crítica de graduandos de diferentes cursos de graduação - Terapia Ocupacional, Pedagogia, Psicologia, Música e Imagem e Som -, que, junto com terapeutas ocupacionais, integraram uma equipe transdisciplinar.

Outras etapas ao mapeamento compuseram o escopo do trabalho, como a elaboração de formaçóes a partir dos dados analisados, voltadas para o aperfeiçoamento de técnicas e estratégias de gestão visando colaborar para a profissionalização criativa dos artistas, bem como a criaçáo de uma rede mais solidária e colaborativa entre eles. Contudo, por não serem objeto de análise neste artigo, não serão abordadas.

As açôes estiveram interessadas na valorização do protagonismo juvenil, com o intuito de proporcionar apoio e fortalecimento à expressáo e autonomia do jovem artista e suas criaçóes. Valorizar uma postura protagonista significa oferecer intervençōes educativas que visem desenvolver agentes responsáveis e interessados 
por movimentos sociais, no papel central de açóes voltadas para benefícios de uma coletividade e que participem ativamente dos processos e proposiçôes (BORBA, 2007).

\section{Procedimentos metodológicos}

O Mapeamento foi realizado em duas etapas. A primeira consistiu num levantamento dos programas, serviços e açóes públicos, privados e ligados ao Terceiro Setor que ofertavam ou cediam espaço para atividades de diversas expressóes artísticas, cujo público-alvo fosse jovem ou sendo estes os protagonistas das atividades culturais. Durante a segunda etapa, foram realizados contatos diretamente com os jovens artistas produtores e/ou gestores culturais, com particular interesse na profissionalização da criatividade.

Para organização do trabalho, os dez estudantes bolsistas coordenaram os trabalhos de cinco miniequipes, que representaram as expressóes artísticas a serem mapeadas: atividades circenses, dança, teatro, música, artes visuais e artes manuais. Destaca-se que, para a formação das miniequipes, além das especificações da graduação, suas áreas de interesse também foram consideradas as aptidóes artísticas e envergaduras militantes no cenário cultural de seus membros.

Para o levantamento dos dados foram realizadas parcerias com órgáos públicos, tais como Coordenadoria de Artes e Cultura, Secretaria Municipal Especial da Infância e da Juventude, Secretaria Municipal de Educação e Secretaria Municipal de Cidadania e Assistência Social da Prefeitura Municipal de São Carlos. Também contribuíram para o levantamento de dados a Oficina Cultural Sérgio Buarque de Holanda, ligada ao Estado de Sáo Paulo, e Pontos de Cultura.

Para o levantamento dos programas, serviços e açôes vinculados ao Terceiro Setor, foram acionadas as organizaçóes não governamentais a partir de uma publicação que apresenta as entidades ligadas ao Terceiro Setor na cidade de São Carlos (TERCEIRO..., 2013), assim como o Serviço Social do Comércio - Sesc e grupos independentes de artistas. Os programas, serviços e açóes do setor privado estiveram voltados para as escolas, academias, produtoras e outros grupos de trabalho autônomos.

O contato com tais serviços e equipamentos visou: a) mapear e identificar as atividades artístico-culturais a partir de suas propostas direcionadas à juventude; b) analisar o potencial dessas atividades para a profissionalização da arte e da cultura; c) compreender o potencial artístico e cultural dos jovens participantes; d) refletir sobre a distribuição geográfica das atividades artístico-culturais encontradas no município.

Foram utilizados dois instrumentos de pesquisa, criados especificamente para este fim: um questionário para o contato com os programas, serviços e açôes, e um roteiro para orientação das entrevistas realizadas com os jovens. O questionário foi aplicado pessoalmente ou por telefone e contribuiu para a padronização dos contatos já levantados, colheu informaçôes sobre as expressóes artísticas e indicou jovens e grupos que atuam profissionalmente na área (Tabela 1).

Todos os jovens e grupos indicados foram contatados, recebendo informaçôes sobre o Mapeamento e sendo convidados a participar. A partir dos retornos foram agendadas entrevistas para contato pessoal com os artistas e grupos. Assim, foi possível realizar as entrevistas e coletar informaçóes mais precisas, envolvendo identificação, relação com a profissionalização, demandas, dificuldades, realizaçóes e perspectivas, além de possíveis indicações de outros jovens/grupos para comporem o Mapeamento (Tabela 2$)^{8}$.

As entrevistas foram gravadas, transcritas e tabuladas. Tendo objetivo específico de identificar quais realmente estavam no perfil, ou seja, jovens ou grupos residentes e atuantes em São Carlos, que visassem a profissionalização da criatividade, pois seriam alvo das próximas etapas interventivas.

Tabela 1. Questões do Questionário I.

\begin{tabular}{ll}
\hline \multicolumn{1}{c}{ Informação a ser coletada } & \multicolumn{1}{c}{ Detalhamento } \\
\hline Expressão artístico-cultural & dança; música; teatro; circo; artes manuais; artes visuais; outras. \\
Identificação & nome do espaço/serviço/local; região; endereço; indicação; nome do \\
& informante; telefone; e-mail/site \\
nopulação-alvo: Atende jovens? & não; sim também; sim apenas. Se sim, faixa etária \\
Atividades realizadas & (resposta aberta) \\
Financiamento & público; privado; terceiro setor; misto \\
Finalidade das atividades & profissionalização; educacional; lazer e convivência; demandas \\
& sociais; outros. \\
nndicações & nome e contato
\end{tabular}


Atividades de planejamento, monitoramento, avaliação, sistematização e compartilhamento foram realizadas durante todo o desenvolvimento do Mapeamento, de forma processual. As aplicaçóes dos roteiros específicos contribuíram para sistematização dos resultados apreendidos pela equipe de trabalho. Realizaram-se encontros semanais de planejamento, estudo, acompanhamento e readequaçôes das estratégias do trabalho de campo e de análise, que representaram espaços democratizados e decisórios que visavam o aprimoramento das açóes feitas.

\section{Resultados}

Foram feitos contatos com 121 equipamentos (60 públicos, 36 privados e 25 do Terceiro Setor). A partir do Mapeamento foram indicados 210 grupos ou artistas individuais que realizam trabalhos com jovens ou protagonizados por eles (194 indicados pelo setor público 9 , 3 pelo privado e 13 pelo Terceiro Setor $)^{10}$.

Analisando o setor público, verificamos que a maior parte das atividades artístico-culturais são voltadas para os jovens (80\%). As expressóes artísticas mais presentes foram dança, teatro, artes manuais e artes visuais, sendo que o intuito na maioria das vezes está voltado para os aspectos educacionais.
Em relação ao setor privado, foi possível identificar que as atividades mais disponibilizadas foram dança e música, também voltadas ao ensino de técnicas. Já no Terceiro Setor, as atividades ofertadas aos jovens (58\%), são em sua maioria voltadas para as artes manuais, música e dança, também relacionado ao ensino, contudo valorizando a convivência e o lazer.

$\mathrm{Na}$ segunda etapa foram realizadas 96 entrevistas com artistas e coletivos de artistas jovens, desses 46 atenderam aos critérios de seleção (Tabela 3).

Através das entrevistas detalhadas, foi possível elencar demandas, dificuldades e encontrar potencialidades e estratégias nos jovens que trabalham diretamente com a profissionalização da criatividade em cada expressão artística, aprofundando as discussōes sobre arte, cultura, juventude e trabalho.

Foram elencados alguns aspectos relativos à análise de cada expressão artística, entendendo as particularidades em relação ao processo de produção, criação e difusão, como também explorando as familiaridades, ou seja, questóes importantes que são apontadas como desafios, verificando que de forma geral, independente da expressão artística, apresentam as mesmas demandas. Serão apresentados os resultados encontrados a partir de cada expressão artística.

Tabela 2. Temas norteadores do Roteiro de Entrevista II.

\begin{tabular}{ll}
\hline \multicolumn{1}{c}{ Temáticas } & \multicolumn{1}{c}{ Questões norteadores e quantidade de perguntas } \\
\hline $\begin{array}{l}\text { Identificação } \\
\text { Sobre histórico }\end{array}$ & $\begin{array}{l}\text { Expressão artístico-cultural; dados do entrevistado (14) } \\
\text { Ano de formação; seu primeiro contato com o grupo; principais apoios; } \\
\text { Estrutura do início; tempo de envolvimento (6) }\end{array}$ \\
grupo & Características do grupo; critérios de entrada ou permanência; formatos de \\
Realização & gestão (5) \\
Objetivos & Atividades centrais, logística dos encontros e trabalho, produtos gerados (4) \\
Profissionalização, & Tipologia do grupo e metas (2) \\
financiamento e recursos & Recursos, financiamento, apoio, patrocínio; dificuldades para a \\
& profissionalização da criatividade e possíveis soluções, relação com \\
comunidade, sonhos e se participa e/ou articula rede cultural (9)
\end{tabular}

Tabela 3. Entrevistas realizadas e grupos de artistas mapeados por expressão.

\begin{tabular}{lcc}
\hline \multicolumn{1}{c}{ Expressão artística } & Entrevistas realizadas & $\begin{array}{c}\text { Artistas jovens que almejam a } \\
\text { profissionalização }\end{array}$ \\
\hline Música & 32 & 16 \\
Dança & 12 & 6 \\
Arte circense & 12 & 7 \\
Teatro & 6 & 3 \\
Artes manuais, visuais e marciais & 34 & 15 \\
TOTAL & $\mathbf{9 6}$ & $\mathbf{4 6}$ \\
\hline
\end{tabular}




\section{A música e sua diversidade}

Em relação aos grupos e artistas relacionados ao campo da música, foram indicados 120 contatos, dos quais 32 foram entrevistados, pois inicialmente se encaixavam no perfil do Mapeamento; os demais possuíam mais de 29 anos, moravam em outra cidade ou ainda não se disponibilizaram para participar da pesquisa ${ }^{11}$. Quando questionados em relação a possíveis articulaçôes com outros grupos e serviços, $23(72 \%)$ grupos afirmaram realizar parcerias e articulaçóes de alguma forma no decorrer de sua carreira artística.

Foram encontrados 16 grupos de música que se encaixaram no perfil, em relação aos estilos musicais, serão apresentadas a relação do grupo de artistas jovens e a quantidade de grupos selecionados interessados na profissionalização da criatividade - rock (15/7), rap (8/6), sound sistem (2/1), experimental (2/0) e outros estilos diversos (5/2). Podemos perceber, portanto, que a maior concentração de jovens que possuem interesse na profissionalização produz rap (75\%).

Dos 16 grupos selecionados, é relevante ressaltar que $60 \%$ deles possuem o objetivo de lazer atrelado ao trabalho e à profissionalização, cerca de $62,5 \%$ deles já haviam desenvolvido ou ainda desenvolvem serviços para comunidade, que variam desde apresentaçóes públicas, oficinas e a oferta de formaçôes específicas.

As principais dificuldades relatadas para a profissionalização variaram desde o reconhecimento comercial do próprio estilo musical que é produzido (como no caso do rap, sound sistem e experimental), à falta de recursos para investir na arte e à dificuldade em poderem se dedicar exclusivamente para a arte que produzem. Dessa forma, foi comum o discurso entre os grupos de exercer outras ocupaçôes informais ou temporárias para obter renda na tentativa de manter a principal ocupação ligada às atividades artísticas, sendo estas desejadas e desempenhadas com satisfação.

No entanto, por mais distante que a profissionalização e o 'viver da música' pareça, os grupos apontam estratégias e motivaçôes que vão muito além da questão financeira (apesar de a estabilidade financeira ser reconhecida e necessária), que adentra a satisfação da produção cultural, a possibilidade de transformação social pela arte e o desejo de expressar e transmitir aos outros reflexôes e sentimentos que mobilizam sensivelmente ${ }^{12}$, essas características permitem aos grupos manterem as motivaçôes para continuar acreditando no trabalho que produzem.

A seguir trechos das entrevistas que ilustram os debates apresentados.
Eu classifico assim o rap mesmo, como assim o que eu faço em si, como transformação, nem artista, você é artista, não né? A gente é transformador social. Porque o que a gente faz com a música vai refletir na vivência e na vida de outras pessoas (S.D., 23 anos).

Mano, meu sonho é... me profissionalizar mesmo na parada, tá ligado?! Viver do rap e ser reconhecido pelo nosso esforço memo,.. Reconhecimento, mano... Reconhecimento que nóis tá no corre não é de hoje, mandando ideia certa, informação, ideia de mil grau, então não é conversinh a fiada e nem fala pra agradar...o que os outro querem ouvir, é a nossa opiniāo, nóis tá ai no dia dia, sofre na pele, temos vários exemplos porque nóis vive o bagulho... Então a gente espera o reconhecimento, se profissionalizar e viver do rap só! (D.V.S., 22 anos).

\section{A dança e seus coletivos}

$\mathrm{Na}$ primeira etapa do mapeamento, foram indicados 32 grupos de dança. Depois do contato inicial e seletivo, 12 grupos passaram pelo processo de entrevista e 6 se encaixaram no perfil do projeto ${ }^{13}$. Ressalta-se o número de componentes dos grupos que juntos somam 87 pessoas envolvidas com esta expressão artística, que desenvolvem os estilos dança de rua, dança do ventre e break.

Todos que almejam a profissionalização intencionam que sua arte possa ser fonte de renda e sustento, entretanto, três grupos/artistas mantêm trabalhos paralelos fora do campo cultural para sobrevivência financeira. Em relação ao financiamento, cinco (83\%) se mantêm com recursos próprios conseguidos através de trabalhos artísticos, workshops, mensalidade dos alunos, e um deles conta com apoios e doaçôes. Os grupos relataram a realização de parcerias com universidades, escolas e outras academias de dança para obtenção de recursos, estruturas físicas ou apresentaçóes, e apenas um deles associou a profissionalização vinculado a projetos sociais.

Entre as dificuldades apontadas pelos artistas, quatro relataram ter dificuldades em conseguir recursos financeiros externos, três citam a falta de reconhecimento. Também foram citadas: a dificuldade em conciliar os trabalhos artísticos com os estudos, a falta de parcerias e a dificuldade de divulgação do trabalho. A venda de shows foi apresentada como estratégia por apenas dois grupos, e metade deles apontou para a necessidade de fomento das políticas públicas culturais.

O sonho de ter o próprio espaço para ensaios, shows e aulas de dança e ser reconhecido por sua 
arte apareceu no discurso de todos os entrevistados, tal como o desejo de obter um maior número de adeptos dessa arte. Entre os desejos e objetivos desses grupos, pode-se elencar a participação em competiçôes dentro e fora da cidade de São Carlos, visto como um meio de divulgação do trabalho e trocas de vivências.

\section{O teatro como expressão consciente}

Foram identificados na primeira etapa 36 grupos que realizavam atividades específicas voltadas para o teatro. Contudo, apenas seis grupos estavam no perfil ${ }^{14}$.

Dentre as múltiplas escolhas sobre o principal objetivo dos grupos, metade dos grupos apresentou: $70 \%$ têm como objetivo a geração de renda, trabalho e profissionalização, oferecer contato, experimentação informal no campo da arte e cultura para outras pessoas; $40 \%$ são voltados às práticas ou movimentos com ideais sociais, políticos e de cidadania e $20 \%$ declaram como objetivo o lazer.

Diante das dificuldades encontradas, todos os grupos mencionam a necessidade de possuírem outros trabalhos para a própria subsistência e ressaltaram a ausência de políticas culturais eficientes que garantam incentivos públicos e privados para a realização de suas atividades. Os próprios grupos também apontam a falta de espaços estruturais no município voltados às diversas necessidades que permeiam o universo do teatro, como ensaio, figurino, iluminação, material de leitura, acervo de cenário, entre outros.

Por outro lado, apesar de todas as dificuldades e responsabilidades, as falas dos artistas evidenciam o caráter da satisfação pessoal que a produção artística proporciona. Os jovens relatam com ênfase as possibilidades de lazer e diversão, transformação social e política e sublimação da vida que o teatro oferece, fazendo com que continuem na luta para execução de seus trabalhos, ressaltando que muitas potencialidades são exploradas de forma mais intensa durante a atividade da atuação. E tal motivo é fator que justifica a continuidade desse fazer mesmo com tantos desafios e demandas presentes. A seguir, trechos das entrevistas que envolvem as reflexóes apontadas.

Que o prazer de fazer o que a gente faz também pode entrar no lazer né. Não é o foco. E poder conquistar mais campos dentro disso, que a gente acha, unanimemente que é uma ferramenta só, de luta, para alguns, ou uma ferramenta de sublimação a vida, vamos colocar assim, para os outros (M. A., 26 anos).
Se a gente conseguir saber que a gente está fazendo uma coisa que está mudando a vida de uma pessoa que não ia no teatro porque como a gente faz, é um grupo que muita gente que faz parte tem uma convivência com pessoas que não são de teatro, que assim não são ligadas no sentido que não frequentam teatro, não sabem o que é teatro. Então, você saber que uma pessoa que tem esse círculo social ela vai tá no teatro e ela vai conseguir levar uma pessoa ou outra que seja para o teatro, eu acho que isso é o maior sonho do grupo assim de saber que as pessoas que estão lá assistindo são pessoas que talvez não teriam contato com o teatro, com arte em geral (H. B., 26 anos).

\section{$11 \mathrm{~A}$ arte circense e o malabarismo dos artistas}

Foram identificados 19 grupos e feitas 12 entrevistas com os grupos selecionados pelos critérios de inclusão da pesquisa ${ }^{15}$. Característica marcante desta expressão está no trabalho individual dos artistas, que mesmo quando se configuram como coletivos, possuem poucos integrantes.

Nas entrevistas foram elencadas dificuldades como a falta de investimento dos diversos segmentos do poder público nas atividades artístico-culturais, fazendo com que os grupos careçam de infraestrutura para exercer suas atividades; o número de editais ofertados também se configura como insuficiente para esses grupos, bem como feedback para os participantes que náo foram selecionados. Diante da questão da falta de financiamento, todos os grupos e artistas apontaram que necessitam exercer outros tipos de trabalhos para sobrevivência (que na maioria possuem elementos precarizantes como falta de carteira assinada, longas jornadas de trabalhos, baixos salários, freelancer, etc.), as dificuldades podem acarretar o abandono da prática da atividade artística, ainda que os desejos e investimentos dos artistas estejam voltados para manutenção e crescimento.

É frequente a apresentação de técnicas circenses como malabares e pirofagia em semáforos e praças, como estratégia de arrecadação monetária. Quatro grupos/artistas relatam praticar essa atividade, embora também exerçam o treino dessas técnicas em detrimento de outras atividades de trabalho não relativas à arte. Porém, reconhecem a precariedade da atividade, assim como os riscos existentes: trânsito de veículos, violência urbana e aqueles decorrentes $\mathrm{da}$ própria atividade, tal como os números de pirofagia, que para além da periculosidade do fogo decorre a utilização de substâncias danosas à saúde. 
Dentre as demandas identificadas pelos grupos, também há a falta formação em outras áreas de conhecimento para a consolidação do grupo (tais como gestão, gerência financeira, logística e produção), bem com a falta de cursos de formaçáo técnica ou superior na área das artes cênicas. A seguir, trecho de entrevista com artista que avaliou sua participação na pesquisa.

Ah, eu queria falar assim que esta pesquisa acho que vai ajudar a dar uma visibilizada na arte, principalmente na questão acadêmica de poder estar buscando um espaço de diálogo dentro da universidade, para debater arte, para pesquisar as questöes artísticas da cidade. Acho que tudo isto ajuda a fortalecer este movimento que eu imagino, assim ele vai se construindo aos poucos, mas que faz a diferença, porque já é um espaço que está falando sobre a arte, que está falando sobre o assunto. E tudo isto ajuda a fortalecer um movimento maior de promoção da arte, de promover a arte como uma coisa constitutiva da cidade e da sociedade. Então, considero muito importante esta pesquisa (L., 26 anos).

\section{Artes visuais, manuais e outras expressões plurais}

Nas expressóes das artes manuais e visuais houve 106 indicações, 34 entrevistas realizadas e 15 grupos e artistas se encaixaram no perfil da pesquisa ${ }^{16}$.

Em especial, esta expressão artística apresentou uma gama de produçóes e diversidade de categorias: artes visuais (13), artes manuais (10), artes plásticas (2), artes manuais e visuais (2), artes manuais, visuais e plásticas (4), artes plásticas e visuais (1), grupo de coworking e grupo de capoeira.

Destes artistas e grupos, $87 \%$ possuem como objetivo a geração de renda, $80 \%$ o trabalho e a profissionalização e $53 \%$ o lazer. Em relação aos financiamentos, oito (54\%) dependem dos investimentos pessoais, seis (40\%) utilizam o próprio lucro com trabalhos para se manterem e um artista citou utilizar as duas estratégias. Quando questionados sobre as demandas para o trabalho com a arte, os grupos mencionam como dificuldades a baixa valorização do trabalho, a falta de incentivo e recursos financeiros, a falta de visibilidade, dificuldade de atingir o público-alvo e da divulgação, não ter uma estrutura apropriada para o trabalho, baixa capacitação dos profissionais, não poderem dedicar-se em tempo integral à arte. Destes grupos e artistas, cinco (34\%) oferecem algum tipo de serviço para a comunidade. Ganhar espaço, crescer profissionalmente, conseguir se manter com a renda do próprio trabalho e semear a arte pelo mundo são alguns dos objetivos e sonhos destes grupos.

Ressalta-se que os grupos voltados para as artes visuais buscam por capacitaçôes e formaçóes técnicas, sete deles relatam essa necessidade, enquanto os das outras categorias não mencionam essa questão tão fortemente. Essa categoria também apresenta as capacitaçôes/formaçôes como estratégia resolutiva, enquanto as outras artes apontam num maior número de respostas a necessidade de incentivo das políticas públicas de forma geral, da política cultural em especial e, ainda, reivindicam primordialmente locais para a exposição de suas produçóes e obras.

Então, acredito que quando a pessoa busca um objetivo, ela tem que buscar isso através da educação. A educação que é eu digo é a sua formação. Seja ela alta formação ou formação através de meios externos. Mas, para que isso aconteça, acredito que o trabalho que tá sendo feito agora, ele já é um passo super importante. Porque lógico, quando sair, e se sair no google acadêmico, eu já vou divulgar e falar eu participei. Eassim outras pessoas vão estar recebendo informaçôes e faz um efeito dominó. Eu acho que a partir de pequenos trabalhos, você consegue alcançar grandes proporçōes $e$ acho bacana o foco que vocês estão tendo nesse trabalho (P.B, 27 anos).

\section{Considerações finais}

Foi possível concluir, a partir das análises, que os jovens têm ocupado os campos da arte e da cultura como produtores, gestores e consumidores, e muitos buscam a profissionalizaçáo da criatividade. Neste percurso, algumas dificuldades são relevantes e apontadas, muitas delas são similares entre os grupos e artistas independentemente da expressão que produzem, entre elas estão: a dificuldade de organização entre a equipe como a autogestão dos trabalhos artísticos; falta de infraestrutura adequada (espaços para ensaios, produção artística, exibição e divulgaçáa); carência de recursos financeiros internos e externos; necessidade de ampliação de público-alvo e da cultura como consumo consciente (que não esteja vinculados aos grandes mercados e mídia, mainstream), necessidade de fortalecimento entre as categorias artísticas, restrição de políticas públicas de incentivo e fomento à arte e cultura que possam alcançar os perfis dos grupos e artistas apresentados neste trabalho.

Das demandas apresentadas, certamente a questão do financiamento surge como grande desafio enfrentado por todos os grupos para conseguirem 'viver da arte', 
sendo que muitos artistas relataram a necessidade de manter um trabalho paralelo à sua arte, dado este de extrema relevância. Na relação dos artistas com suas carreiras autônomas, foi possível identificar obstáculos relacionados à gestão de trabalho, uma vez que o artista precisa de outras formaçóes, tais como administração, gestão financeira, comunicação, experiências com processos burocráticos e jurídicos, além das equipes reduzidas para realizar tarefas dessas envergaduras, cujas funções são sobrepostas às artísticas, para as quais os interesses estão voltados.

Em decorrência da falta de oportunidades e incentivos para esses artistas, atualmente há uma competição pelo mercado que corrobora para a individualização dos problemas e limitação nas perspectivas dos trabalhos. É necessário identificar a emergência de políticas públicas que apoiem e promovam a profissionalização da criatividade como possíveis estratégias para grupos jovens.

Os sonhos e desejos de realizações também apareceram frequentemente nos discursos dos jovens entrevistados, estando ligados às realizaçóes da carreira artística, ao reconhecimento e valorização do seu trabalho e à vontade de semear a arte, conseguir ter visibilidade, atingir mais pessoas pelo mundo e compartilhar seus processos de criação. As açóes visando as transformaçôes ideológicas, políticas e sociais, a satisfação, a diversão e a sublimação da vida fortalecem esses jovens na luta pela profissionalização de sua arte.

Aspectos relevantes se encontram nos apontamentos da equipe executora do Mapeamento, ou seja, dos jovens envolvidos diretamente na busca dos dados e contatos, entrevistas e aproximaçóes com os artistas. Nos relatórios de sistematização, acompanhamento e avaliação, aspectos importantes foram pontuados considerando sua formação profissional e pessoal. Alguns dos itens indicados foram: a formação transdisciplinar da equipe como um fator multiplicador das pluralidades, das vivências e das trocas de experiências; a criação de espaços para discussóes das açôes e para acolhimento das demandas; a importância da possibilidade de trabalhar com a arte e com a cultura no universo acadêmico, já que são raras as oportunidades e a valorização da integração da universidade em relação às questóes sociais, focalizando possíveis impactos sob a ótica das políticas culturais.

Todos esses aspectos colaboraram para a construção de novos conhecimentos técnicos e científicos, para troca de saberes entres os campos e pessoas envolvidas e para a produçáo de deslocamentos sensíveis que disparam reflexóes sobre a profissionalização da criatividade na juventude.
Em relação à formação de terapeutas ocupacionais na cultura, foram percebidos aspectos relevantes que envolvem a pertinência deste profissional e sua atuação no campo da cultura, considerando suas dimensôes econômica, simbólica e cidadã, pois o enfoque aos sujeitos em atividade necessariamente se refere a fazeres múltiplos instaurados na cultura. A conexão entre trabalho, educação, processos criativos e profissionalização da criatividade se delinearam como estratégia para o terapeuta ocupacional interessado nos processos de inclusão, nas linguagens artísticas e de expressão e de valorização de potencialidades, produzindo uma rede de possibilidades formativas para a prática profissional. Fazendo com que a experimentação ativa desse processo já na graduação, com os alunos em processo de construção e reflexão acerca de suas constituiçóes e açóes profissionais futuras, seja extremamente válida e necessária.

\section{Referências}

ALMEIDA, M. I. M.; PAIS, J. M. Criatividade, juventude e novos horizontes profissionais. Rio de Janeiro: Jorge Zahar Editor, 2012.

BORBA, P. L. O. Protagonismo. In: PARK, M. B.; FERNANDES, R. S.; CARNICEL, A. (Org.). Palavras-chave em educação não-formal. Campinas: Unicamp, 2007. p. 241-242.

BRASIL. Ministério da Cultura. Política Nacional de Juventude: diretrizes e perspectivas. Sáo Paulo: Conselho Nacional de Juventude, 2006. Disponível em: <http:// www.secretariageral.gov.br/atuacao/juventude/politica-nacional>. Acesso em: 8 jun. 2015.

BRASIL. Ministério da Cultura. Economia e Política Cultural: acesso, emprego e financiamento. Brasília, 2007. Disponível em: <http://www.cultura.gov.br/documents/10883/38605/cpc-volume-03.pdf/643124a6-d5ef-4d90-b2db-a1c9c96ae536>. Acesso em: 8 jun. 2015.

BRASIL. Ministério da Cultura. Plano Nacional da Cultura: metas do Plano Nacional da Cultura. Brasília, 2010. Disponível em: <http://www.cultura.gov.br/plano-nacional-de-cultura-pnc>. Acesso em: 19 fev. 2015.

BRASIL. Ministério da Cultura. Plano da Secretaria da Economia Criativa: políticas, diretrizes e açóes 2011 2014. Brasília, 2011. Disponível em: <http://www.cultura.gov.br/documents/10913/636523/plano+da+secret aria+da+economia+criativa/81dd57b6-e43b-43ec-93cf-2a29be1dd071>. Acesso em: 8 jun. 2015.

BRASIL. Secretaria Nacional de Juventude. Aprovação do Estatuto da Juventude: um imenso legado para o Brasil. Disponível em: <http://www.juventude.gov.br/ sg_juventude_juventude/juventude/noticias/ultimas_ noticias/2013/07/10-07-2013-aprovacao-do-estatuto-da-juventude-um-imenso-legado-para-o-brasil/view $>$. Acesso em: 15 jul. 2013. 
BRASIL. Ministério da Cultura. Sistema Nacional de Informaçōes e Indicadores Culturais (SNIIC). Disponível em: <http://www.cultura.gov.br/sistema-nacional-de-informacoes-e-indicadores-culturais-sniic $>$. Acesso em: 5 mar. 2015.

CANCLINI, N. G. Reconstruir políticas de inclusão na América Latina. In: ORGANIZAÇÃO DAS NAÇÓES UNIDAS PARA A EDUCAÇÃO, A CIÊNCIA E A CULTURA. Politicas culturais para o desenvolvimento: uma base de dados para a cultura. Brasília: UNESCO, 2003. p. 21-42.

COELHO, T. Banco de dados: do inerte cultural à cultura da vida. In: ORGANIZAÇÃO DAS NAÇŌES UNIDAS PARA A EDUCAÇÃO, A CIÊNCIA E A CULTURA. Políticas culturais para o desenvolvimento: uma base de dados para a cultura. Brasília: UNESCO, 2003. p. 217-232.

CORROCHANO, M. C. et al. Jovens e trabalho no Brasil: desigualdade e desafios para a política pública. São Paulo: Ação Educativa/Instituto ibi, 2008. Disponível em: <http://www.bdae.org.br/dspace/bitstream/123456789/2301/1/Jovens_trabalho_Brasil.pdf>. Acesso em: 8 jun. 2015.

CORROCHANO, M. C. Jovens trabalhadores: expectativas de acesso ao ensino superior. Avaliação, Sorocaba, v. 18 , n. 1, p. 23-44, 2013.

COSTANZI, R. N. Trabalho decente e juventude no Brasil. Brasília: Organização Internacional do Trabalho OIT, 2009.

DE MASI, D. Criatividade e grupos criativos. Fantasia e concretude. Rio de Janeiro: Sextante, 2002.

FÓRUM UNIVERSAL DA CULTURA. Agenda 21 da cultura: cidades e governos locais unidos. Barcelona: Comissão da Cultura, 2004. Disponível em:<http:// www.agenda21 culture.net/index.php/pt/docman/ agenda21/9-ag21 cptpdf/file>. Acesso em: 17 maio 2015.

GROPPO, L. A. Condição juvenil. In: PARK, M. B.; FERNANDES, R. S.; CARNICEL, A. (Org.). Palavras-chave em educação não-formal. Campinas: Unicamp, 2007. p. 91-92.

INSTITUTO BRASILEIRO DE GEOGRAFIA E ESTATÍSTICA - IBGE. Projeção da população do Brasil por sexo e idade 1980-2050. Rio de Janeiro, 2008. Disponível em: <www.ibge.gov.br/censo2010>. Acesso em: 19 fev. 2015.

LINS, C. P. C. Indicadores Culturais: possibilidades e limites. Brasília: Ministério da Cultura, 2006. Disponível em: <http://www.cultura.gov.br/docu- ments/10883/38605/edc_cristinapereira_1148588640. pdf/f4663acf-76b7-48b7-bbf8-e65751b5bfe8>. Acesso em: 10 maio 2015 .

MARCÍliO, M. L. História da escola em São Paulo e no Brasil. São Paulo: Instituto Braudel, 2005.

ORGANIZAÇÃO DAS NAÇÓES UNIDAS - ONU. Millennium Development Goal Achievement Fund. Youth, Employment and Migration MDG-F Thematic Study: Review of Key Findings and Achievements. 2013 Disponível em: <http:/www.mdgfund.org/sites/default/ files/YEM_Thematic\%20Study.pdf $>$. Acesso em: $20 \mathrm{fev}$. 2015.

ORGANIZAÇÃO INTERNACIONAL DO TRABALHO - OIT. Trabalho decente e juventude. In: ORGANIZAÇÃO INTERNACIONAL DO TRABALHO. Diagnóstico situação da juventude no Brasil. Brasília, 2009. Disponível em: <http://www.oitbrasil.org.br/ sites/default/files/topic/youth_employment/pub/trabalho_decente_juventude_brasil_252.pdf>. Acesso em: 19 jan. 2014

PAIS, J. M. A construção sociológica da juventude: alguns contributos. Análise Social, Lisboa, v. 25, n. 1-2, p. 139-165, 1990

PORTAL BRASIL. Cultura é ferramenta para incentivar desenvolvimento econômico. Brasília, 2009. Disponível em: <http://www.brasil.gov.br/cultura/2009/10/cultura-e-ferramenta-para-incentivar-desenvolvimento-economico>. Acesso em: 17 maio 2015.

REIS, A. C. F. (Org.). Economia criativa como estratégia de desenvolvimento: uma visão dos países em desenvolvimento. Itaú Cultural: Garimpo de Soluções, 2008.

SILVA, C. R.; LOPES, R. E. Adolescência e Juventude: entre conceitos e políticas públicas. Cadernos de Terapia Ocupacional da UFSCar, São Carlos, v. 17, n. 2, p. $87-$ 106, 2009.

SOUZA, M. M; CARRIERI, A. P. Racionalidades no fazer artístico: estudando a perspectiva de um grupo de teatro. RAE-Revista de Administração de Empresas, São Paulo, v. 51, n. 4, p. 382-395, 2011.

TERCEIRO SETOR SÃO CARLOS. Guia de instituiçóes, trabalhos e informaçóes voltadas à promoção e ao desenvolvimento social. São Carlos: SENAC, 2013.

UNESCO. Creative economy report: widening local development pathways. United Nations/UNDP/UNESCO, 2013. Disponível em: <http://www.unesco.org/culture/ pdf/creative-economy-report-2013.pdf>. Acesso em: 19 fev. 2015.

\section{Contribuição dos Autores}

Carla Regina Silva, Isadora Cardinalli e Marina Sanches Silvestrini foram responsáveis pela orientação do trabalho e pelas análises realizadas. Aline Zacchi Farias, Débora Isabele de Vasconcelos Teixeira, Ana Carolina da Silva Almeida Prado, Letícia Ambrosio, Rúbia Diana da Mota, Caio de Camargo Ishido, Marco Antonio Liu Targa Mancini realizaram as coletas e contribuíram nas análises dos dados. Todos os autores são responsáveis pela redação do texto e aprovaram sua versão final. 


\section{Fonte de Financiamento}

Programa de Extensão Universitária PROEXT SESU MEC (2013-2014).

\section{Notas}

${ }^{1}$ Documento com vocação mundial que busca estabelecer as bases de um compromisso das cidades e dos governos locais para o desenvolvimento cultural, foi aprovada em 2004 em Barcelona, no primeiro Fórum Universal das Culturas.

${ }^{2} \mathrm{O}$ conceito de economia criativa origina-se do termo indústrias criativas, por sua vez inspirado no projeto Creative Nation, da Austrália, de 1994. Entre outros elementos, este defendia a importância do trabalho criativo, sua contribuição para a economia do país e o papel das tecnologias como aliadas da política cultural (REIS, 2008).

${ }^{3}$ A meta 11 do Plano Nacional da Cultura é: aumentar em 95\% no emprego formal do setor cultural, isto porque a grande parte dos trabalhadores da cultura não têm emprego formal, com registro em carteira ou mesmo outro tipo de contratação (BRASIL, 2013).

${ }^{4}$ Trata-se de plataforma virtual gerenciada pelo Ministério da Cultura, cujo objetivo é possibilitar o acesso às informaçôes do segmento cultural de forma centralizada, além de fornecer metodologias e estabelecer parâmetros para a mensuração da atividade do campo cultural e das necessidades sociais por cultura.

${ }^{5}$ O Programa foi aprovado e financiado por meio do Edital do Programa de Extensão Universitária PROEXT da Secretaria de Ensino Superior, do Ministério da Educação (2013-2014), e apoiado pela Pró-Reitoria de Extensão da Universidade Federal de São Carlos, realizado pelo Laboratório de Atividades Humanas e Terapia Ocupacional do Departamento de Terapia Ocupacional da Universidade Federal de São Carlos.

${ }^{6}$ Trata-se de Pesquisa 'guarda-chuva' que integrou as pesquisas de Iniciação Científica: Juventude, Empreendimentos Criativos e Tecnologia Social (2013-2014); Jovens Atores Teatrais: o trabalho e a profissionalização da criatividade (2013-2014); O Hip-Hop é uma Família Só: juventude, trabalho e profissionalização da criatividade. (2014-2015) e Prelúdios sobre Formação Artística: a profissionalização da criatividade de artistas circenses, com apoio dos programas de Iniciação Científica da Pró-Reitoria de Pesquisa da Universidade Federal de São Carlos e do Conselho Nacional de Desenvolvimento Científico e Tecnológico (CNPq).

${ }^{7}$ A ACIEPE foi ofertada para 35 estudantes e interessados da comunidade externa à universidade, durante o primeiro semestre de 2014, e contribuiu para a articulação das açôes de pesquisa, ensino e extensão, por meio de encontros teóricos, práticos e trabalho de campo, no qual miniequipes tiveram oportunidades de conhecer e participar das açóes de pesquisa e extensão com jovens artistas da cidade.

${ }^{8}$ Ressalta-se que todos os procedimentos éticos foram respeitados, a pesquisa foi aprovada pelo Comitê de Ética de Pesquisa com Seres Humanos, Processo No. 426.473. Todos os informantes que colaboraram com a pesquisa autorizaram suas participaçôes, anuindo os Termos de Consentimento Livre e Esclarecido.

${ }^{9}$ Ressaltam-se as indicaçóes realizadas pela Oficina Cultural Sérgio Buarque de Holanda, que disponibilizou um número considerável de contatos alimentados por anos de atuação no campo da cultura.

${ }^{10}$ É provável que possam existir outras atividades não mapeadas na cidade, porém elas carecem de sistematização e compartilhamento, o que dificulta o repasse fidedigno das informaçóes quando solicitadas.

${ }^{11}$ Não responderem às tentativas de contato e quatro pessoas se recusaram ou não puderam participar.

${ }^{12}$ Os grupos reconhecem a arte como canal de expressão e comunicação, que pode transmitir ideias e afetos, para além da consciência racional estabelecida nesta relação. Pode sensibilizar, pois utiliza-se de diferentes linguagens estéticas.

${ }^{13}$ Entre os grupos que não foram entrevistados, as principais causas foram: a finalidade do grupo era apenas o lazer; o grupo não tinha jovens ou o grupo não atuava mais.

${ }^{14}$ Dentre os motivos que os identificaram fora do perfil estavam: dados desatualizados, indicaçóes repetidas, ausência de respostas, recusaram-se ou não puderam participar da pesquisa, grupos e artistas acima dos 29 anos e não residentes em São Carlos.

${ }^{15}$ Dentre os motivos que os identificaram fora do perfil estavam: artistas acima dos 29 anos, ausência de retorno dos contatos realizados, três grupos fazem trabalhos voluntários no hospital e não possuem interesse na profissionalização, grupos que não se identificaram com esta expressão artística.

${ }^{16}$ Dentre os motivos que os identificaram fora do perfil estavam: ausência de retorno dos contatos realizados, dados desatualizados ou incorretos, não trabalham mais na cidade de São Carlos, participantes acima de 29 anos, não possuir a profissionalização como um objetivo, grupos que se encaixaram em outras expressóes e uma recusa ao convite de participação. 